Stefanos Kanatsios ORCID iD: 0000-0002-4547-2816

Outcomes of definitive resection for stage IV melanoma

\author{
Stefanos Kanatsios
}

University of Melbourne

\title{
Neutrophil to lymphocyte ratio is an independent predictor of outcome for patients undergoing definitive resection for stage IV melanoma
}

Stefanos Kanatsios BSc MD, Melbourne Melanoma Project, Connie S. N. Li Wai Suen BMathStatSc PhD, Jonathan Simon Cebon MBBS FRACP PhD, David Gyorki MBBS MD FRACS

1. Austin Health, Heidelberg, Vic., Australia

2. Olivia Newton-John Cancer Research Institute, La Trobe University School of Cancer Medicine, Heidelberg, VIC 3084, Australia.

3. University of Melbourne, Parkville, Vic., Australia

Full name of Author: Dr Stefanos Kanatsios Academic Degrees: BSc, MD Postal address: 41 Victoria Parade, Fitzroy, 3065, VIC, Australia Telephone nu: +61421782986 Email address: stefanos.kanatsios@gmail.com

Full name of Author: Melbourne Melanoma Project Academic Degrees:

Postal address: MMP, Peter MacCallum Cancer Centre, Locked Bag 1

This is the author manuscript accepted for publication and undergone full peer review but has not been through the copyediting, typesetting, pagination and proofreading process, which may lead to differences between this version and the Version of Record. Please cite this article as doi: 10.1002/jso.25138. 
A'Beckett Street, VIC, Australia Telephone nu: +61385596530 Email address: info@melbournemelanomaproject.com

Full name of Author: Connie S. N. Li Wai Suen Academic Degrees:

BMathStatSc, PhD Postal address: La Trobe University, Bundoora, 3086, VIC, Australia Telephone nu: +613 94791180 Email address:

C.LiWaiSuen@latrobe.edu.au

Full name of Author: Professor Jonathan Simon Cebon Academic Degrees: MBBS FRACP PhD Postal address: Level 5, ONJ Centre, 145 Studley Road, Heidelberg, 3084, VIC, Australia Telephone nu: +6139496 5462 Email address: jonathan.cebon@onjcri.org.au

Full name of Author: Mr David Gyorki Academic Degrees: MBBS MD FRACS Postal address: 305 Grattan Street, Melbourne, 300, VIC, Australia Telephone nu: +61414409145 Email address: david.gyorki@petermac.org

Running Title: Outcomes after metastasectomy for melanoma

Funding: MMP was supported by the Victorian Government through the Victorian Cancer Agency Translational Research Program.

\section{Conflict of interest: Nil}

Table of Contents synopsis: Through retrospective analysis, this study highlights prolonged survival outcomes in a subset of patients who underwent surgical resection of melanoma metastases. Multivariable analysis demonstrates an association between lower neutrophil to lymphocyte ratios and favorable survival outcomes following metastasectomy. 


\section{Abstract: \\ Background and Objectives:}

The aim of this study was to perform a retrospective analysis of survival rates and determine prognostic indicators for patients who underwent definitive surgical resection of stage IV melanoma.

\section{Methods:}

Patients included were those who underwent complete resection of metastatic melanoma. Data was analyzed using IBM SPSS 2.0. Survival estimates were derived from Kaplan-Meier, Log-Rank and Breslow tests.

\section{Results:}

The study population $(n=95)$ consisted of 60 males and 35 females. Median overall survival (OS) from the first metastasectomy was 49 months $(95 \% \mathrm{Cl}$, 31-67 months). Overall survival at 1, 2 and 5 years was 92, 87 and 50\% respectively. Predictors of survival included clear surgical margins compared to patients with positive margins (median OS 53 vs. 20 months, $P=0.026$ ). A preoperative Neutrophil to Lymphocyte Ratio less than 5 experienced a median OS of 65 months compared to 15 months $(P=0.006$; multivariable analysis for OS: HR 3.590, $\mathrm{P}=0.009)$.

\section{Conclusion:}

This study's results are consistent with previous findings demonstrating favourable long-term outcomes following selective resection of metastatic melanoma. In addition to achieving clear surgical margins, a low preoperative 
Neutrophil to Lymphocyte Ratio was associated with improved outcomes. These factors may help identify surgical candidates.

Key Terms: Metastatic Melanoma, Stage IV Melanoma, Metastasectomy, Survival, Neutrophil to Lymphocyte

\section{Introduction:}

The management of patients with metastatic melanoma has evolved with the introduction of new effective systemic agents [1]. Treatment selection involves consideration of the disease biology and tempo of disease progression. The American Joint Committee of Cancer (AJCC) staging system stratifies patients with stage IV melanoma according to anatomical location of metastatic disease. The outcomes for patients with stage IV melanoma are heterogeneous regardless of substage with some patients displaying low volume indolent disease and others demonstrating rapid progression.

The optimal treatment strategy for patients with metastatic melanoma will differ according to a number of factors including patient age and comorbidities as well as tumour volume and growth kinetics. Surgical resection of oligometastatic disease with curative intent is an important consideration in carefully selected patients after consideration of these and other factors. Long-term disease control has been shown in prior studies in a highly selected subset of patients. The prospective Southwest Oncology Group (SWOG) and Malignant Melanoma Active Immunotherapy Trial (MMAIT-IV) demonstrated 5 year survival rates of $29-42.3 \%$ [2, 3]. These studies focused on complete resections and demonstrated the importance of appropriate candidate selection. 
The aim of this study was to analyze long term follow up data for a large single center series and identify prognostic markers for patients who underwent definitive resection of stage IV melanoma.

\section{Materials and Methods:}

Patient information was collected from the Melbourne Melanoma Project and Austin Hospital Melanoma databases. Protocols were approved by the Austin Health Human Research Ethics Committee. The study period extended from 1982 to 2016. Patients were identified within these melanoma databases using the search term metastatic.

Patients were included if they underwent surgical resection of stage IV disease and were rendered disease free. Stage IV disease was categorized according to the American Joint Committee on Cancer $7^{\text {th }}$ edition (AJCC) [4]. Only resections with curative intent were included and were defined by the resection of all radiological evident disease. Patients undergoing palliative surgical resection were excluded. Patients where the primary melanoma was cutaneous in origin were included, excluding ocular and mucosal melanomas. A censored event was classified as the death of a patient.

Outcomes were reported for events subsequent to the first metastasectomy even if multiple surgical resections were undertaken. Comprehensive chart review was performed collecting data on primary tumor characteristics, location, extent of metastatic disease and preoperative laboratory values. Lactate Dehydrogenase values were not collected due to unavailable data. Surgical information was gathered from operative notes and histology reports. Preoperative laboratory values were only included in the analysis if they were 
collected within two weeks of surgery. Neutrophil to Lymphocyte Ratio (NLR) was categorized with a prespecified cutpoint of 5 and Absolute Lymphocyte Count (ALC) with a cutpoint of $1.9 \times 10^{9} / \mathrm{L}$ according to prior publications [5]. Disease Free Interval (DFI) was calculated from the date of most recent surgery (wide excision of primary or resection of stage III disease depending on the patient's history) to the date of metastasectomy for stage IV disease. Patients with unknown primaries were excluded from the DFI cohort unless they had prior stage III disease.

Using IBM SPSS Statistics for Windows, Version 22.0, overall survival (OS) was calculated by Kaplan-Meier estimates. Overall survival was determined from the date of the first metastasectomy to the date of death or last follow up. Extended survival periods were cut off at 120 months. Univariable analysis was performed using Log-rank tests. Variables analyzed included patient demographics, primary tumor characteristics and metastatic disease characteristics.

Multivariable analysis was performed using a cox regression model. Alongside preoperative variables with a long-rank $P$-value $<0.200$, categories included in analysis were; gender, age, stage III disease progression, number of organ systems and nodules involved at the time of metastasectomy.

\section{Results:}

\section{Patient Population:}

281 patients were identified. 186 patients were excluded leaving a selected study population of 95 patients. Exclusion criteria included; non-cutaneous 
primary disease $(n=5)$, individuals that did not have stage IV disease at the time of resection ( $n=95)$, underwent a palliative operation $(n=72)$ or had a follow up period of less than 6 months $(n=14)$.

Most patients were male (63\%) with a median age at melanoma diagnosis of 48 years (13-80 years). Primary tumor characteristics are highlighted in Table

1. The median DFI to stage IV disease was 33 months $(\mathrm{Cl} 95 \%, 27-40$ months). Median age at time of surgery was 57 years (16 - 79 years).

Forty-eight individuals (51\%) had intervening resected stage III disease; 37 (77\%) with stage IIIB disease and $11(23 \%)$ with stage IIIC melanoma. The median DFI from primary disease to stage III disease was 28 months ( 1 - 150 months).

\section{Stage IV Disease:}

At the time of initial stage IV diagnosis, $24 \%, 27 \%$ and $49 \%$ patients had stage IV M1a, M1b and M1c disease respectively. $87 \%$ of patients in this cohort had only 1 organ system involved. The remaining patients had 2 organ systems involved, with the majority of these cases involving visceral disease as well as either a skin/subcutaneous or lymph node metastasis.

\section{Metastasectomy:}

Majority (86\%) of operations took place prior to the year 2011.Specific sites of resected metastatic disease are given in Table 2. The most common sites of resected disease were lung, skin/subcutaneous tissue and brain. 
63 of the 95 patients had resections of only 1 tumor nodule. Two separate cases involved the resection of 9 subcutaneous lesions and 11 gastrointestinal lesions and lymph nodes.

Most cases were elective, with only 14 operations deemed urgent, predominantly for brain and gastrointestinal resections. Clear margins were obtained in $93 \%$ of cases. All but one urgent metastascetomy were able to achieve clear margins. Only four patients were noted to have significant perioperative complications, including a pulmonary embolism and post operative pyrexia.

\section{Systemic Treatment}

15 patients underwent systemic therapy prior to their first metastasectomy. This did not include stage III adjuvant treatment. The majority of these patients $(66 \%)$ were treated with experimental vaccines, four were treated with chemotherapeutic agents and one received combination BRAF and MEK inhibitors (Dabrafenib and Trametinib). Analysis highlighted no difference in post-metastasectomy survival in these patients compared to the remainder of the cohort $(P=0.336)$.

The majority $(n=60 ; 63 \%)$ of the cohort was treated with systemic therapy at some point following their metastasectomy. 17 patients were treated with contemporary first line agents; BRAF and MEK inhibitors $(n=11)$ and PD-1 monoclonal antibody therapy $(n=6) .53$ patients received systemic therapy prior to the modern era, including chemotherapy $(n=31)$, a variety of vaccine trials $(n=11)$ and use of single agent CTLA-4 inhibitors $(n=11)$. Treatment 
involving a combination of the above mentioned therapies was noted in 34 patients.

\section{Outcomes:}

After a median follow up of 90 months ( $95 \% \mathrm{Cl}, 80-100$ months), median OS from time of metastasectomy was 49 months $(95 \% \mathrm{Cl}, 31-67$ months) (Figure 1A). One year, two year and five year survival was 92, 87 and 50\% respectively.

At the time of last follow up, 30 patients (32\%) remained free of disease (Table 2). Of these patients, 3 had surgery for M1a disease, 11 had M1b disease and 16 had M1c disease. The median OS of these groups was 58 (0 - 140), $78(32-124)$ and $68(41-94)$ months respectively. Of those patients who remain disease free, 16 patients had more than one metastasectomy (range 2-7). One patient underwent seven small bowel resections over an eight year period for recurrent small bowel disease. This patient remains disease free six years following their last metastasectomy.

On univariable analysis, factors associated with an improvement in OS were resections with clear histological margins (Median OS 53 vs. 20 months, $\mathrm{P}=$ 0.030 ) and a neutrophil to lymphocyte ratio (NLR) of less than or equal to five $(P=0.006)$. The association of NLR with OS was also seen on multivariable analysis (HR 3.590, $\mathrm{P}=0.009)$ (Table 3). These values are further reinforced through a stepwise regression analysis ( $\mathrm{HR} 3.755, \mathrm{P}=0.007)$. Information on preoperative NLR was present in 41 patients and those patients with a NLR $\leq 5$ $(n=31)$ had a median OS of 65 months compared to those patients with NLR $>5(n=10)$ with median OS of 15 months (Figure 1B). The importance of 
clear surgical margins is further emphasized by the significant $(P=0.030)$ impact on OS highlighted on multivariable analysis. The initial site and stage of the first metastasectomy played no role in survival outcomes $(P=0.189)$, although there was an unexplained non-signficant trend towards worse survival outcomes in the non-visceral group $(\mathrm{P}=0.082)$. When outcomes were compared for patients who underwent resection prior to 2011 with those after 2011, no difference in OS was seen $(P=0.854)$. Furthermore, the number of organ systems involved at the time of the operation and the number of nodules resected had no association with survival outcomes ( $P=0.321)$. Primary tumor characteristics, the presence of intervening stage III disease and patient demographics did not impact OS following complete metastacetomy of stage IV melanoma (Table 3).

\section{Discussion:}

This study reports a single center experience of metastasectomy for stage IV melanoma with a median survival of 49 months. As far back as 1982 , analogous studies have demonstrated protracted survival rates of up to 23 months following resection [6-8]. Patients from the large Multicenter Selective Lymphadenectomy Trial (MSLT-1) study who underwent subsequent surgical resection for recurrent stage IV disease achieved a 4 year survival of $45.7 \%$ [9]. The MSLT-1 study however was limited by its retrospective nature as well as not differentiating between definitive and palliative operations. The prospective SWOG and MMAIT-IV studies limited these biases and described extended disease control in their highly selected population groups (31\% 4 year OS and $42.3 \% 5$ year OS respectively) [2, 3].The MMAIT-IV study was 
further extended by Faries et al to determine the OS impact of an allogenic whole-cell vaccine (Canvaxin) with bacillus Calmette-Guerin (BCG), following complete resection of Stage IV melanoma. The trial demonstrated an increased survival duration in the placebo arm compared to the treatment arm (44.9\% 5 year OS versus $39.6 \% 5$ year OS). Both of these groups with stage IV disease had a longer than expected survival [10]. Both of these studies highlight the role of surgery in a carefully selected subset of patients with metastatic melanoma.

To achieve prolonged survival outcomes following metastasectomy, complete surgical resection is important highlighting the need for careful preoperative planning and patient selection [11]. The current study identified that a complete, margin-negative resection is associated with improved survival. Hena et al demonstrates similar findings with a $12 \%$ difference (14\% vs. $2 \%)$ in 5 year OS between complete and incomplete resections [7]. Furthermore, our findings are consistent with previous studies that have shown no association in outcomes linked to the number of organ systems involved and number of tumor nodules resected $[2,3,12]$. Taken together, these findings highlight the importance of preoperative imaging and planning to optimize patient selection for surgical resection [13]. In the absence of the need for symptom control, surgery is not indicated for patients where clear margins cannot be achieved.

Melanoma is the $3^{\text {rd }}$ most common cancer to spread to the brain, with intracranial metastasis seen in up to $46 \%$ of patients with stage IV disease [14]. One of the surprising findings of this study was that $34 \%$ of patients 
undergoing resection of brain metastases achieved prolonged disease control. Patients with M1C disease, specifically brain metastasis have a very poor prognosis [15]. This data however supports the consideration of disease resection in selected patients with brain metastasis. There are a number of hypotheses for the biologic rationale of surgical metastasectomy. These include a reduction in tumour burden to better allow an immune response to control micrometastatic disease [11]. Additionally, higher neutrophil levels inhibit immune cells which are involved in tumour eradication. These cells include lymphocytes, T cells and Natural Killer cells [16]. A NLR $\leq 5$ is a surrogate marker for a robust immune response and an association between an elevated NLR and poor prognosis has been highlighted in other tumour types [16-20]. We found a greater than 4-fold survival difference when comparing patients with NLR $\leq 5$ versus NLR>5. This is consistent with a previous study of patients undergoing surgical resection of intra-abdominal melanoma metastases (NLR $>5$ vs. $\leq 5$, Median OS 5 and 26 months respectively) [5]. The NLR may therefore aid in the selection of optimal surgical candidates. Furthermore, patients with resected stage IV melanoma have been eligible for a number of adjuvant studies [21]. Patient stratification with pre-operative NLR in these studies should be considered.

Many of the patients in this series were treated prior to the current era of effective systemic therapy agents. A number of small studies have demonstrated the role of surgical resection of isolated progressive metastatses in the setting of otherwise stable disease following systemic therapy $[22,23]$.Case reports have also described a neoadjuvant approach to render a tumour resectable $[24,25]$. It is clear that patient selection for up- 
front metastasectomy in the modern era is important to provide optimal individualised care.

The retrospective nature of this study introduces a number of limitations. Unfortunately certain data points were not recorded due to the extended study period. Lead-time bias is also likely as improved imaging and preoperative work-up would have led to a difference in patterns of patient selection during the course of the study period. Lead-time bias attributed to surgical advancements is minimized in this study as the cohort looks at complete resections. This is further supported by the similar results seen between our study and older studies. In addition, the analysis comparing the pre and post 2011 modern therapy era is underpowered. Further research and larger cohorts are required to address the correlation between metastasectomy, NLR and advanced modern treatments. It is also important to consider selection bias as patients with better performance status and limited metastases will naturally be candidates for surgical resection.

\section{Conclusion:}

For patients with stage IV melanoma, a multidisciplinary approach is required to consider optimal treatment planning which in carefully selected patients should include surgical resection of oligometastatic disease. A NLR less than or equal to 5 is associated with significantly better outcomes and this biomarker should be validated in larger cohorts to confirm its role in patient selection. 


\section{References:}

1. Maverakis E, Cornelius LA, Bowen GM, Phan T, Patel FB, Fitzmaurice $\mathrm{S}$, et al. Metastatic melanoma - a review of current and future treatment options. Acta Derm Venereol. 2015;95(5):516-24.

2. Sosman JA, Moon J, Tuthill RJ, Warneke JA, Vetto JT, Redman BG, et al. A phase 2 trial of complete resection for stage IV melanoma: results of Southwest Oncology Group Clinical Trial S9430. Cancer. 2011;117(20):474006.

3. Morton DL TJ, Kelly M, et al., editor MMAIT-IV Clinical Trial Group. Multicenter double-blind phase 3 trial of Canvaxin vs. placebo as post surgical adjuvant in metastatic melanoma. Society of Surgical Oncology 59th Annual Cancer Symposium; 2006; San Diego, California.

4. Balch CM, Gershenwald JE, Soong S-j, Thompson JF, Atkins MB, Byrd DR, et al. Final version of 2009 AJCC melanoma staging and classification. Journal of clinical oncology. 2009;27(36):6199-206.

5. Cananzi FC, Dalgleish A, Mudan S. Surgical management of intraabdominal metastases from melanoma: role of the neutrophil to lymphocyte ratio as a potential prognostic factor. World Journal of Surgery. 2014;38(6):1542-50.

6. Feun LG, Gutterman J, Burgess MA, Hersh EM, Mavligit G, McBride $\mathrm{CM}$, et al. The natural history of resectable metastatic melanoma (Stage IVA melanoma). Cancer. 1982;50(8):1656-63. 
7. Hena MA, Emrich LJ, Nambisan RN, Karakousis CP. Effect of surgical treatment on stage IV melanoma. American Journal of Surgery. $1987 ; 153(3): 270-5$.

8. Ollila DW, Hsueh EC, Stern SL, Morton DL. Metastasectomy for recurrent stage IV melanoma. Journal of Surgical Oncology. 1999;71(4):20913.

9. Howard JH, Thompson JF, Mozzillo N, Nieweg OE, Hoekstra HJ, Roses DF, et al. Metastasectomy for distant metastatic melanoma: analysis of data from the first Multicenter Selective Lymphadenectomy Trial (MSLT-I). Annals of Surgical Oncology. 2012;19(8):2547-55.

10. Faries MB, Mozzillo N, Kashani-Sabet M, Thompson JF, Kelley MC, DeConti RC, et al. Long-Term Survival after Complete Surgical Resection and Adjuvant Immunotherapy for Distant Melanoma Metastases. Ann Surg Oncol. 2017;24(13):3991-4000.

11. Ollila DW. Complete metastasectomy in patients with stage IV metastatic melanoma. Lancet Oncology. 2006;7(11):919-24.

12. Ollila DW, Gleisner AL, Hsueh EC. Rationale for complete metastasectomy in patients with stage IV metastatic melanoma. Journal of Surgical Oncology. 2011;104(4):420-4.

13. Schule SC, Eigentler TK, Garbe C, la Fougere C, Nikolaou K, Pfannenberg C. Influence of (18)F-FDG PET/CT on therapy management in patients with stage III/IV malignant melanoma. Eur J Nucl Med Mol Imaging. 2016;43(3):482-8.

This article is protected by copyright. All rights reserved. 
14. Amer $\mathrm{MH}, \mathrm{Al}$-Sarraf M, Baker LH, Vaitkevicius VK. Malignant melanoma and central nervous system metastases: incidence, diagnosis, treatment and survival. Cancer. 1978;42(2):660-8.

15. Nicholas S, Mathios D, Jackson C, Lim M. Metastatic melanoma to the brain: surgery and radiation is still the standard of care. Current Treatment Options in Oncology. 2013;14(2):264-79.

16. Liao W, Zhang J, Zhu Q, Qin L, Yao W, Lei B, et al. Preoperative Neutrophil-to-Lymphocyte Ratio as a New Prognostic Marker in Hepatocellular Carcinoma after Curative Resection. Translational oncology. $2014 ; 7(2): 248-55$

17. Wang S, Zhang Z, Fang F, Gao X, Sun W, Liu H. The neutrophil/lymphocyte ratio is an independent prognostic indicator in patients with bone metastasis. Oncology letters. 2011;2(4):735-40.

18. Yamanaka T, Matsumoto S, Teramukai S, Ishiwata R, Nagai Y, Fukushima M. The baseline ratio of neutrophils to lymphocytes is associated with patient prognosis in advanced gastric cancer. Oncology. 2007;73(34):215-20.

19. Sarraf KM, Belcher E, Raevsky E, Nicholson AG, Goldstraw P, Lim E. Neutrophil/lymphocyte ratio and its association with survival after complete resection in non-small cell lung cancer. The Journal of thoracic and cardiovascular surgery. 2009;137(2):425-8.

20. Sharaiha RZ, Halazun KJ, Mirza F, Port JL, Lee PC, Neugut Al, et al. Elevated preoperative neutrophil:lymphocyte ratio as a predictor of 
postoperative disease recurrence in esophageal cancer. Ann Surg Oncol. 2011;18(12):3362-9.

21. Weber J, Mandala M, Del Vecchio M, Gogas HJ, Arance AM, Cowey

CL, et al. Adjuvant Nivolumab versus Ipilimumab in Resected Stage III or IV Melanoma. New England Journal of Medicine. 2017;377(19):1824-35.

22. He M, Lovell J, Ng BL, Spillane J, Speakman D, Henderson MA, et al. Post-operative survival following metastasectomy for patients receiving BRAF inhibitor therapy is associated with duration of pre-operative treatment and elective indication. J Surg Oncol. 2015;111(8):980-4.

23. Gyorki DE, Yuan J, Mu Z, Zaidi B, Pulitzer M, Busam K, et al. Immunological insights from patients undergoing surgery on ipilimumab for metastatic melanoma. Annals of Surgical Oncology. 2013;20(9):3106-11.

24. Koers K, Francken AB, Haanen JBAG, Woerdeman LAE, van der Hage JA. Vemurafenib As Neoadjuvant Treatment for Unresectable Regional Metastatic Melanoma. Journal of Clinical Oncology. 2013;31(16):e251-e3.

25. Kaidar-Person O, Eran A, Bar-Sela G. Complete pathologic response after neoadjuvant treatment with vemurafenib for malignant melanoma. Journal of the American Academy of Dermatology. 2014;70(2):e39-41. 


\section{Figure:}

Fig. 1a Overall survival of patients who underwent resection of stage IV melanoma ( $n=95$, Median survival 49 months, 5-year survival 50\%). Fig 1b. Overall survival of individuals with a Neutrophil to Lymphocyte (NLR) $\leq 5$ ( $n=$ 31, Median survival 65 months) compared to a NLR $>5$ ( $n=10$, Median survival 15 months $)(P=0.006)$.
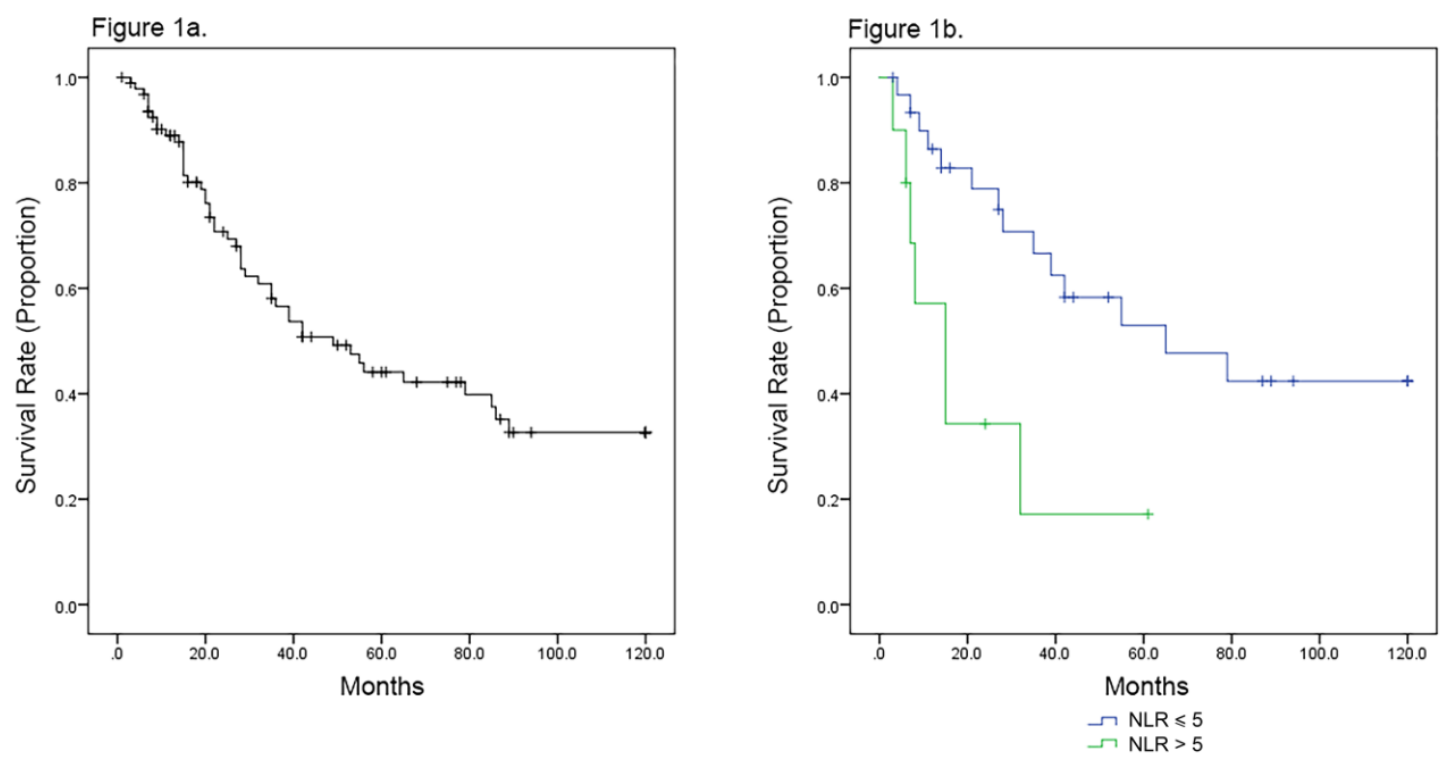

This article is protected by copyright. All rights reserved. 
Table I. Demographics, Primary and Stage IV Disease Characteristics

\begin{tabular}{|c|c|}
\hline Characteristic & No. \\
\hline \multicolumn{2}{|l|}{ Gender } \\
\hline Female & $35(37 \%)$ \\
\hline Male & $60(63 \%)$ \\
\hline Median Age (years) at Diagnosis & 48 \\
\hline \multicolumn{2}{|l|}{ Initial Stage } \\
\hline 1 & 18 \\
\hline II & 32 \\
\hline III & 3 \\
\hline IV & - \\
\hline Unknown Primary & 24 \\
\hline \multicolumn{2}{|l|}{ Primary Type } \\
\hline Nodular Melanoma & 18 \\
\hline Superficial Spreading Melanoma & 29 \\
\hline Desmoplastic Melanoma & 2 \\
\hline Acral Lentiginous Melanoma & 1 \\
\hline Leniginous Maligna Melanoma & 2 \\
\hline \multicolumn{2}{|l|}{ Primary Site } \\
\hline Head \& Neck & 13 \\
\hline Lower Limb & 14 \\
\hline Upper Limb & 13 \\
\hline Trunk & 30 \\
\hline
\end{tabular}

This article is protected by copyright. All rights reserved. 


\section{Clarke Level}

I 2

II 2

$\begin{array}{ll}\text { III } & 20\end{array}$

$\begin{array}{ll}\text { IV } & 27\end{array}$

$\begin{array}{ll}\mathrm{V} & 8\end{array}$

Ulceration

Yes

No

\section{Breslow Thickness}

$>4 \mathrm{~mm}$

$\leq 4 \mathrm{~mm}$

47

\section{Stage 3 Progression}

Yes

$48(51 \%)$

No

$47(49 \%)$

\section{Stage IV Diagnosis}

M1a

$23(24 \%)$

M1b

$26(27 \%)$

M1c

$46(49 \%)$

Visceral vs. Non-Visceral

Visceral

$72(76 \%)$

Non-Visceral

$23(24 \%)$

\section{Number of Organ Systems}

This article is protected by copyright. All rights reserved. 
Table II. Metastasectomy and Subsequent Outcomes

\begin{tabular}{|c|c|}
\hline Characteristic & No. (\%) \\
\hline \multicolumn{2}{|c|}{ Site of Metastasectomy } \\
\hline Skin/Subcut & 20 \\
\hline Lymph Nodes & 7 \\
\hline Lung & 26 \\
\hline Liver & 1 \\
\hline GIT & 13 \\
\hline Brain & 19 \\
\hline Other & 18 \\
\hline \multicolumn{2}{|c|}{ Nu of Resected Nodules } \\
\hline 1 & $63(66 \%)$ \\
\hline$>1$ & $32(34 \%)$ \\
\hline \multicolumn{2}{|l|}{ NLR $>5$} \\
\hline Yes & 10 \\
\hline No & 31 \\
\hline
\end{tabular}

This article is protected by copyright. All rights reserved. 


\begin{tabular}{|c|c|}
\hline Yes & 12 \\
\hline No & 29 \\
\hline \multicolumn{2}{|l|}{ Clear Margins } \\
\hline Yes & $89(93 \%)$ \\
\hline No & $6(7 \%)$ \\
\hline \multicolumn{2}{|l|}{ Outcomes } \\
\hline \multicolumn{2}{|l|}{ Disease Progression } \\
\hline Yes & $65(68 \%)$ \\
\hline No & $30(32 \%)$ \\
\hline \multicolumn{2}{|l|}{ Outcome } \\
\hline No Evidence of Disease & $29(32 \%)$ \\
\hline Alive with Disease & $3(2 \%)$ \\
\hline Died with Disease & $47(49 \%)$ \\
\hline Lost to Follow Up & $15(16 \%)$ \\
\hline Died from another Cause & $1(1 \%)$ \\
\hline
\end{tabular}

This article is protected by copyright. All rights reserved. 
Table III. Univariant and Multivariant Analysis of Variables effecting Overall Survival

\begin{tabular}{|c|c|}
\hline \multicolumn{2}{|l|}{ Univariable log-rank Analysis } \\
\hline Demographics and Primary Diagnosis & P-value \\
\hline Gender & 0.762 \\
\hline Age ( $<60$ vs. $>60$ years) & 0.993 \\
\hline Stage at Initial Diagnosis & 0.449 \\
\hline Unknown Primary vs. Known & 0.558 \\
\hline Type & 0.404 \\
\hline Location & 0.154 \\
\hline H\&N & 0.005 \\
\hline UL & 0.545 \\
\hline LL & 0.617 \\
\hline Trunk & 0.559 \\
\hline Clarke Level & 0.415 \\
\hline Ulceration & 0.880 \\
\hline Breslow Thickness (<4mm vs. $>4 \mathrm{~mm}$ ) & 0.941 \\
\hline \multicolumn{2}{|l|}{ Metastatic Disease Characteristics } \\
\hline Stage 3 Progression & 0.528 \\
\hline Stage IV Disease & 0.189 \\
\hline Number of Organ systems & 0.321 \\
\hline \multicolumn{2}{|l|}{ Metastasectomy Characteristics } \\
\hline Disease Progression > 12 months & 0.135 \\
\hline
\end{tabular}

This article is protected by copyright. All rights reserved. 


\begin{tabular}{|c|c|c|}
\hline Visceral vs Non-Visceral resection & 0.08 & \\
\hline 1 resected nodule vs $>1$ & 0.59 & \\
\hline NLR $>5$ & 0.00 & \\
\hline $\mathrm{ALC}>1.9 \times 10^{9} / \mathrm{L}$ & 0.13 & \\
\hline Clear Margins & 0.02 & \\
\hline Urgent vs. Elective & 0.40 & \\
\hline Multivariable Cox-Regression Analys & & \\
\hline Variable & Hazard Ratio & P-Value \\
\hline Male vs. Female & 0.605 & 1.1433 \\
\hline Age at Metastasectomy (>60 vs $<60$ & 0.680 & 0.722 \\
\hline ( & 0.868 & 1.055 \\
\hline Location of Primary & 2.789 & 0.007 \\
\hline - Head \& Neck & 0.831 & 1.141 \\
\hline Prior Stage III Disease & 0.472 & 1.659 \\
\hline DFI to Stage IV (< 12 vs. $>12$ mos) & 0.243 & 0.369 \\
\hline Stage at Metastasectomy & 0.563 & 0.082 \\
\hline Visceral vs. Non-Visceral Metastases & 3.590 & 0.009 \\
\hline NLR (> 5 vs. $\leq 5)$ & & \\
\hline $0^{9}$ yc $\left.<10 \times 10^{9}\right)$ & 0.941 & 0.938 \\
\hline ALC ( $>1.9 \times 10$ VS. $(1.9 \times 10)$ & 0.129 & 6.997 \\
\hline Number oт organ systems (I VS. >I) & 0.182 & 0.388 \\
\hline $\begin{array}{l}\text { Number of resected Nodules (1 vs. >1) } \\
\text { Margins (Complete vs. Incomplete) }\end{array}$ & 0.307 & 0.030 \\
\hline
\end{tabular}

This article is protected by copyright. All rights reserved. 


\section{University Library}

\section{- M M I N E R VA \\ A gateway to Melbourne's research publications}

Minerva Access is the Institutional Repository of The University of Melbourne

Author/s:

Kanatsios, S;Project, MM;Suen, CSNLW;Cebon, JS;Gyorki, DE

Title:

Neutrophil to lymphocyte ratio is an independent predictor of outcome for patients undergoing definitive resection for stage IV melanoma

Date:

2018-11-01

Citation:

Kanatsios, S., Project, M. M., Suen, C. S. N. L. W., Cebon, J. S. \& Gyorki, D. E. (2018). Neutrophil to lymphocyte ratio is an independent predictor of outcome for patients undergoing definitive resection for stage IV melanoma. JOURNAL OF SURGICAL ONCOLOGY, 118 (6), pp.915-921. https://doi.org/10.1002/jso.25138.

Persistent Link:

http://hdl.handle.net/11343/284446 